\title{
Intervención psicológica para mejorar el disfrute en una joven deportista de Fit Kid
}

\author{
Ana Sánchez Plazas \\ Aspsicóloga.com. Valencia, España \\ Enrique Cantón Chirivella \\ Universidad de Valencia, España
}

RESUMEN: El presente estudio tiene como objetivo evaluar la eficacia de una intervención psicológica para mejorar el rendimiento en una deportista de 13 años $(n=1)$ que practica Fit Kid. La demanda inicial de la deportista se refiere a "No rindo, no me divierto". Para abordar el caso, se ha realizado una evaluación pre y post intervención. Los instrumentos empleados fueron la escala PACES y el cuestionario CPRD. La intervención está realizada desde una aproximación cognitivo-conductual, empleando técnicas y estrategias como la reestructuración cognitiva, la relajación, la imaginería, el establecimiento de objetivos y auto-registros conductuales. Los resultados indican que una clara mejoría del disfrute y del rendimiento a partir de las diferencias de puntuación en los instrumentos. Se concluye que las técnicas cognitiva-conductual son eficaces para la mejora del disfrute y el rendimiento de los jóvenes deportistas, por lo que es relevante integrar el entrenamiento psicológico en la preparación deportiva habitual en los clubes deportivos..

PALABRAS CLAVES: intervención, rendimiento, disfrute, cognitivo-conductual, fit kid

\section{Psychological intervention to improve enjoyment in a young Fit Kid athlete}

ABSTRACT: The present study aims to evaluate the efficacy of a psychological intervention to improve performance in a 13-year-old athlete $(n=1)$ practicing Fit Kid. The athlete's initial claim refers to "I don't give up, I don't have fun." To address the case, a pre-and-post intervention evaluation was carried out. The tools used were the PACES scale and the CPRD questionnaire. The intervention is carried out from a cognitive-behavioral approach, using techniques and strategies such as cognitive restructuring, relaxation, imagery, goal setting and behavioral self-records. The results indicate a clear improvement in enjoyment and performance from the differences in scores in the tools. It is concluded that cognitive-behavioral techniques are effective for improving the enjoyment and performance of young athletes, so it is relevant to integrate psychological training in routine training in sports clubs.

KEYWORDS: intervention, performance, enjoyment, cognitive-behavioral, fit kid

\section{Intervenção psicológica para melhorar a satisfação numa jovem atleta de Fit Kid}

RESUMO: O presente estudo tem como objetivo avaliar a eficácia de uma intervenção psicológica para melhorar o rendimento numa atleta de 13 anos ( $n=1)$ praticante de Fit Kid. A afirmação inicial da atleta refere "Não rendo, não me divirto". Para abordar o caso, foi realizada uma avaliação antes e após a intervenção. Os instrumentos utilizados foram a escala PACES e o questionário CPRD. A intervenção foi realizada a partir de uma abordagem cognitivo-comportamental, utilizando técnicas e estratégias como a reestruturação cognitiva, relaxamento, a imaginação, a definição de objetivos e o autorregistro comportamental. Os resultados indicam uma nítida

\footnotetext{
Ana Sánchez Plazas es psicóloga Experta acreditada Psicología del Deporte (COP). Associació de Psicologia de l'Esport de la Comunitat Valenciana y psicóloga en aspsicóloga.com. Valencia.
}

Enrique Cantón Chirivella es psicólogo y Dr. en Psicología en Departamento Psicología Básica, Universidad de Valencia.

La correspondencia sobre este artículo debe enviarse a Ana Isabel. Sánchez Plazas C/Espinosa n8, despacho 103. Valencia. E-mail: anasanpl@cop.es 
melhoria na satisfação e no rendimento a partir das diferenças nas pontuações nos instrumentos. Concluiu-se que as técnicas cognitivo-comportamentais são eficazes para melhorar a satisfação e o rendimento de jovens atletas, sendo relevante integrar o treino psicológico na preparação desportiva habitual nos clubes desportivos..

PALAVRAS-CHAVE: intervenção, rendimento, satisfação, cognitivo-comportamental, fit kid

Artículo recibido: 19/07/2021 | Artículo aceptado: 09/11/2021

La Federación Española de Baile Deportivo 2021, define el Fit Kid como una especialidad de reciente incorporación y cuyo inicio en Europa fue en 1990 llegando a España en 1996 (Federación española de Baile de Salón, 2021). Entre sus técnicas están los saltos, giros, equilibrios, acrobacias y estilos de danza diferentes siguiendo el ritmo de la música. Asimismo, se desarrollan de forma excepcional cualidades físicas como la flexibilidad, la fuerza y la resistencia, así como la coordinación, el sentido del ritmo y la expresión corporal. Tiene un gran componente artístico, lo que lo convierte en un deporte muy vistoso y espectacular, donde los aspectos psicológicos tienen su relevancia (motivación, concentración, confianza, etc.)

Las posibilidades de intervención psicológica actuales precisan de profesionales debidamente preparados y acreditados que se adapten a las demandas reales del cada vez más cambiante mundo del deporte (Cantón, 2016). Las principales estrategias empleadas para la mejora del rendimiento son las de orientación cognitiva-conductual, como, por ejemplo, la reestructuración cognitiva, el auto registro, la visualización guiada y el establecimiento de metas.

Por medio de la reestructuración cognitiva (García y Rajo, 2020) se establecen comparaciones entre las creencias irracionales y desadaptadas y otras más adaptadas con el objetivo de que se produzca un cambio cognitivo en la manera de pensar. Los autorregistros se utilizan en la Psicología para tomar conciencia de un comportamiento concreto y observar la realidad objetiva (Weinberg y Gould, 2010). Esta herramienta ha sido muy útil ya que aporta información de primera mano de la deportista y fueron cumplimentados en el club de entrenamiento. En el uso de la visualización guiada o imaginería, se ha tenido en cuenta que esta herramienta tiene efectos positivos en el aprendizaje de la técnica y táctica deportiva como puede ser el control cognitivo y emocional, la focalización atencional, así como el establecimiento de metas (Cox, 2009). Por otra parte, el plan de entrenamiento se adapta a una consecución de metas orientadas a fomentar el disfrute de la deportista, como "declaraciones de intencionalidad" como por ejemplo "quiero pasármelo bien" (Weinberg y Gould, 2010).

Esta novedosa actividad deportiva (Fit Kid) implica la necesidad de avanzar en su conocimiento en profundidad, así como de establecer las variables psicológicas implicadas que la caracterizan, siendo un ejemplo más de la tendencia actual de ampliar con nuevas posibilidades profesionales esta área aplicada de la Psicología, tal y como indica Cantón, $(2010,2016)$. En este sentido, y antes de la intervención, se ha realizado un estudio para conocer a fondo esta disciplina y comprender qué variables podrían estar implicadas en su práctica (asistencia a entrenamientos y competiciones, entrevistas a deportistas y entrenadores). De igual modo, supone aplicar la Psicología científica, de manera eficaz y adaptada al contexto deportivo o al rendimiento humano (García-Naveira y Cantón, 2020).

El entrenamiento mental (como parte más del entrenamiento deportivo) se ha incluido en el programa de trabajo de muchos deportistas y equipos deportivos (Peris y Cantón, 2018). Con el entrenamiento mental se persigue que el deportista aprenda estrategias psicológicas que le permitan, por un lado, afrontar las diferentes situaciones deportivas y por otro responder adecuadamente ante estas demandas (Olivares y López, 2016). Asimismo, una de las claves para el éxito deportivo es, precisamente, el disponer de un buen repertorio de habilidades y de recursos psicológicos que le permitan al deportista gestionar adecuadamente los requerimientos deportivos (Olmedilla y Dominguez, 2016).

Este estudio se ha centrado en la variable disfrute, que se refiere al estado positivo del afecto que refleja sentimientos como el placer, el gusto y la diversión durante la actividad físico-deportiva, la cual se asocia con un mayor rendimiento y adherencia a la actividad. El disfrute en el deporte se puede definir como un estado afectivo positivo, ya sea más cognitivo o fisiológico, que implica sentimientos de placer y diversión asociados con la realización de actividades físico deportiva. (Mokaberian et al., 2018). Las emociones agradables favorecen el rendimiento (Cantón y Checa, 2012), por lo que asociarlas a distintas situaciones relacionadas con el desempeño es una habilidad que mejora el funcionamiento.

En los últimos años cabe citar investigaciones centradas en el estudio de las variables afectivas y emocionales como el disfrute, la motivación, la actitud o la autoestima (Sallis et 
al., 2000), relacionándose con un óptimo estado psicológico, que lleva a realizar una actividad principalmente por sí misma (Kimiecik y Harris, 1996). Diferentes modelos teóricos han integrado este constructo como uno de los componentes de influencia en la actividad física y el deporte, si bien con diferente perspectiva. El disfrute según Ryan y Deci (2000), está considerado como un factor regulador del proceso motivacional. De igual modo, también se ha situado el disfrute como un factor importante para el compromiso con el deporte (Scanlan et al., 1993). Otros autores se refieren al disfrute como una dimensión de las actitudes (Subramanian y Silverman, 2000) o como un factor asociado con la competencia percibida (Davison et al., 2007).

Por todo ello, en el presente trabajo se parte de la hipótesis de que el disfrute está relacionado con el rendimiento de la deportista, especialmente teniendo en cuenta su edad, ya que es ampliamente reconocido que la adolescencia es una fase del ciclo de la vida en donde las modificaciones físicas y psicológicas afectan al desarrollo personal, produciéndose importantes cambios en las actitudes, estando en un momento vital del desarrollo, donde los retos afectivo-emocionales comienzan a explicar el comportamiento de la conducta humana (Miras, 2001). De igual modo, el final de la infancia y el principio de la adolescencia forman una etapa en la que el abandono de la actividad física-deportiva se suele poner de manifiesto. Por otra parte, algunos autores concluyen que la sensación de disfrute es uno de los principales motivos de práctica deportiva en edad escolar y que los adolescentes buscan fundamentalmente la diversión, el placer de jugar y el perfeccionamiento de sus aptitudes (HeIlín et al., 2006; Martín et al., 2014).

El marco teórico utilizado en esta intervención es el propuesto por la terapia cognitivo-conductual, utilizada por una buena parte de los profesionales de la Psicología del Deporte (Faggiani et al., 2016). Desde este enfoque, se considera que los sesgos interpretativos del procesamiento de la información tienen una función destacada en el desarrollo y mantenimiento de problemas psicológicos, asimismo que el cambio cognitivo es fundamental para que el resultado de la intervención sea eficaz. Asimismo, se admite que existen de tres tipos distintos de conocimientos en diferentes niveles de procesamiento cognitivo, como las creencias, las reglas y pensamientos automáticos (McArdle y Moore, 2012).

El objetivo del presente trabajo es presentar un estudio de caso único, en el que se realiza una evaluación pre y pos-intervención, en una deportista de 13 años, cuya demanda inicial era mejorar su rendimiento, así como divertirse practicando Fit kid. Se espera que después de intervención realizada la deportista compita mejor y tenga una mejor vivencia positiva en los entrenamientos y competiciones, asimismo logre aprender habilidades psicológicas para fomentar su futuro deportivo dada la temprana edad de la deportista.

\section{Método}

Este trabajo muestra la intervención psicológica en un diseño de caso único A-B-A con una joven deportista de 13 años, utilizando una metodología de triangulación metodológica (Castañer et al., 2013). La metodología llevada a cabo en este estudio es la sugerida para estudios de caso único (Stake, 2020) en cuya base está la intervención cualitativa, con el apoyo de instrumentos cuantitativos para aumentar la fiabilidad y validez de los resultados (Simons, 2011).

\section{Participante}

El participante ha sido una adolescente de 13 años que estudia $2^{\circ}$ de Educación Secundaria Obligatoria E.S.O. y que es integrante de un club de Fit Kid. La deportista también es competidora. Se trata de un deporte que practican niñas desde los cuatro años, que combina danza, acrobacias y gimnasia deportiva y que requiere un elevado sentido del ritmo.

Se trata de un deporte de competición, que puede realizarse de forma individual y por equipos. En este trabajo nos centramos en la faceta individual ya que no compite en equipo. Los entrenamientos se llevan a cabo en un polideportivo, efectuándose 4 sesiones de entrenamiento por semana por las tardes, con una duración de 2 horas cada una. El fin de semana acude a competiciones locales.

El profesional que realizó la intervención psicológica es una psicóloga licenciada en psicología, experta en Psicología del Deporte acreditada como experta por el Consejo General de la Psicología de España y tiene veinte años de experiencia en intervención psicológica en el ámbito del deporte.

\section{Instrumentos}

El disfrute se midió usando el cuestionario PACES (Physical Activity Enjoyment Scale) de Kendzierski y DeCarlo (1991), adaptado a población de chicas adolescentes españolas y validada por García et al. (2008) desarrollando una versión corta (6 ítems), que proporciona datos sobre dos factores:

Factor 1: Motivación primaria, que incluye tres ítems concernientes a la motivación intrínseca relacionada con el disfrute en formato bipolar (Ítem 1. Me interesa /me aburro, Ítem 2. Me gusta/no me gusta, Ítem 3. Es muy divertido/no es nada divertido). 
Factor 2: Percepción de disfrute, integra tres ítems, relacionados con la percepción de sensaciones vinculadas al disfrute (Ítem 4. Me siento muy bien físicamente cuando practico/me siento muy mal físicamente cuando practico, Ítem 5. Me hace sentir muy activa/no me hace sentir nada activa, Ítem 6. Me hace sentir realizada/no me hace sentir realizada), incorporando así un componente afectivo).

La puntuación máxima para los dos factores es de 15 puntos y el mínimo es de 5 puntos para los ítems positivos y de -15 a -5 para los ítems negativos. Si analizamos la escala Paces en su totalidad la puntuación oscilaría entre 30 puntos y -30 puntos.

En el análisis de la fiabilidad de cada uno de sus factores se obtuvo un $p$. $a=.81$ para el primer factor y $a=.71$ para el segundo.

Para la evaluación de la percepción psicológica del rendimiento se utilizó el cuestionario de Características Psicológicas para el Rendimiento Deportivo -CPRD- (Gimeno y Buceta, 2010), formado por 55 ítems de cinco alternativas, que aporta medidas sobre Influencia en la Evaluación del Rendimiento, Control del Estrés, Motivación, Habilidad Mental y Cohesión de Equipo. La escala de cohesión de equipo no ha sido utilizada, ya que la deportista no compite en esa modalidad.

El instrumento presenta un coeficiente a de Cronbach de 85. Se ha utilizado este cuestionario siguiendo las recomendaciones del autor, en el contexto de una intervención individual.

\section{Procedimiento}

Los padres, asesorados por el entrenador, contactan con el psicólogo. El motivo de la demanda es que la deportista no tiene ilusión y observan un rendimiento peor (tiene más fallos); además, le cuesta mucho acudir a los entrenamientos y muchas veces pone excusas para no ir. En esta conversación relatan que se trata de un deporte poco conocido. En primer lugar, se concierta una entrevista con ambos padres, quienes refieren que no quieren ver a su hija triste y que no les importa que abandone el deporte.

El siguiente contacto es con la deportista, quien sostiene como motivo de acudir, que no se divierte y que por eso comete tantos fallos. A partir de aquí, se establecen las condiciones de la intervención de acuerdo con los horarios de entrenamiento. La deportista acudirá una vez a la semana y se harán sesiones de trabajo psicológico antes del entrenamiento y después del mismo.

La intervención se realizó mediante un enfoque cognitivo-conductual, que otorga mucha importancia a los deter- minantes de la conducta y a sus consecuencias. Se lleva a cabo un análisis funcional de la conducta en el deporte basado en su experiencia. El objetivo del análisis funcional era determinar qué estímulos precedentes originaban que no hubiese disfrute y sus consecuencias.

En este trabajo importante identificar los componentes fisiológicos, cognitivos y conductuales para detectar los diferentes niveles en el análisis funcional, a nivel conductual, cognitivo y fisiológico. En un proceso de evaluación- intervención, el psicólogo/a del deporte aplica diferentes instrumentos y procedimientos (cuestionarios, batería de test, observación, entrevistas, etc.) para evaluar psicológicamente al deportista, tanto en su vertiente personal como deportiva (Ezquerro, 2015).

Para ello, se crean auto-registros ad hoc asimismo, se realizan entrevistas semi-estructuradas adaptadas. Las técnicas cognitivas, la cumplimentación de registros y la restructuración cognitiva son efectuadas siguiendo las sugerencias de Labrador et al. (2001). Entre las herramientas cognitivas se introducen ideas potenciadoras (Peris, 2020), en particular aquellas cuyo contenido está relacionado con el disfrute y el auto-éxito.

Se ha utilizado la técnica de visualización ya que puede ayudar a mejorar la motivación (Weinberg y Gould, 2010), en este caso se han utilizado imágenes cuya finalidad era que la deportista se visualizara disfrutando del deporte y así incrementar la motivación y con ello su rendimiento, concretamente visualización de imágenes cognitivo específicas (imaginarse efectuando bien pasos de la coreografía) así como imágenes cognitivo generales ("me lo paso bien en el tatami") siguiendo el esquema planteado por Weinberg y Gould (2010).

La visualización este estudio también se usa para mejorar la focalización de la atención hacia estímulos gratificantes, en otro trabajo de Yalcin y Ramazanoglu (2020), se utilizaron imágenes para incrementar la confianza de los deportistas y, por lo tanto, útil para la mejora del rendimiento deportivo. Antes de la intervención se le explicó en qué consistía la misma.

También se contó con el consentimiento de la deportista, la cual estuvo implicada en todas las fases de la intervención. Asimismo, ambos padres firmaron un consentimiento informado.

Se realizaron un total de 16 sesiones de 1 hora cada una, con una frecuencia de una por semana, en el despacho profesional de la psicóloga que reunía las condiciones necesarias (temperatura, ruido e iluminación). En la Tabla 1 se presenta un resumen de las sesiones y las técnicas empleadas. 
Tabla 1. Resumen de la intervención en Fit Kid $(n=1)$

\begin{tabular}{|c|c|c|}
\hline Sesiones & Contenido & Objetivos \\
\hline 1 & Entrevista padre, madre y deportista. & Toma de contacto y exposición de la demanda \\
\hline 2 у 3 & Entrevista con la deportista & Historial deportivo \\
\hline 4 y 5 & $\begin{array}{l}\text { Aplicación de los cuestionarios (PACE y CPRD), } \\
\text { autorregistros y análisis funcional }\end{array}$ & Evaluación tiempo 1 \\
\hline 6 y 7 & $\begin{array}{l}\text { Análisis de la evaluación en tiempo } 1 \\
\text { Reestructuración cognitiva }\end{array}$ & Establecer hipótesis de trabajo. \\
\hline 8 y 9 & $\begin{array}{l}\text { Ejercicio de Disfrute } \\
\text { Explicación sesgos atencionales } \\
\text { Atención al disfrute y descripción }\end{array}$ & $\begin{array}{l}\text { Enseñar a disfrutar focalizando su atención a "pequeños disfrutes" } \\
\text { Auto-observación de desempeño con registros } \\
\text { Registro actividades agradables }\end{array}$ \\
\hline 10 y 11 & $\begin{array}{l}\text { Análisis objetivos entrenos } \\
\text { Plan de entrenamiento }\end{array}$ & Establecimiento de objetivos \\
\hline 12 & Trabajo con emociones & Aceptar y gestionar las emociones \\
\hline 13 & $\begin{array}{l}\text { Análisis capacidad de imaginar } \\
\text { Elaboración de escenas imaginación }\end{array}$ & Visualización guiada entrenamientos con disfrute \\
\hline 14 & $\begin{array}{l}\text { Aplicación de los cuestionarios (PACE y CPRD), } \\
\text { autorregistros y análisis funcional }\end{array}$ & Evaluación tiempo 2 \\
\hline 15 & Analizar evaluación tiempos 1 y 2 & Establecer las cuestiones positivas del proceso de intervención y mejorías \\
\hline 16 & Seguimiento & Hacer un acompañamiento tras la intervención y ver evolución. \\
\hline
\end{tabular}

Tabla2. Análisis Funcional utilizando el cuestionario CPRD, escala I. E. R. y auto-registro

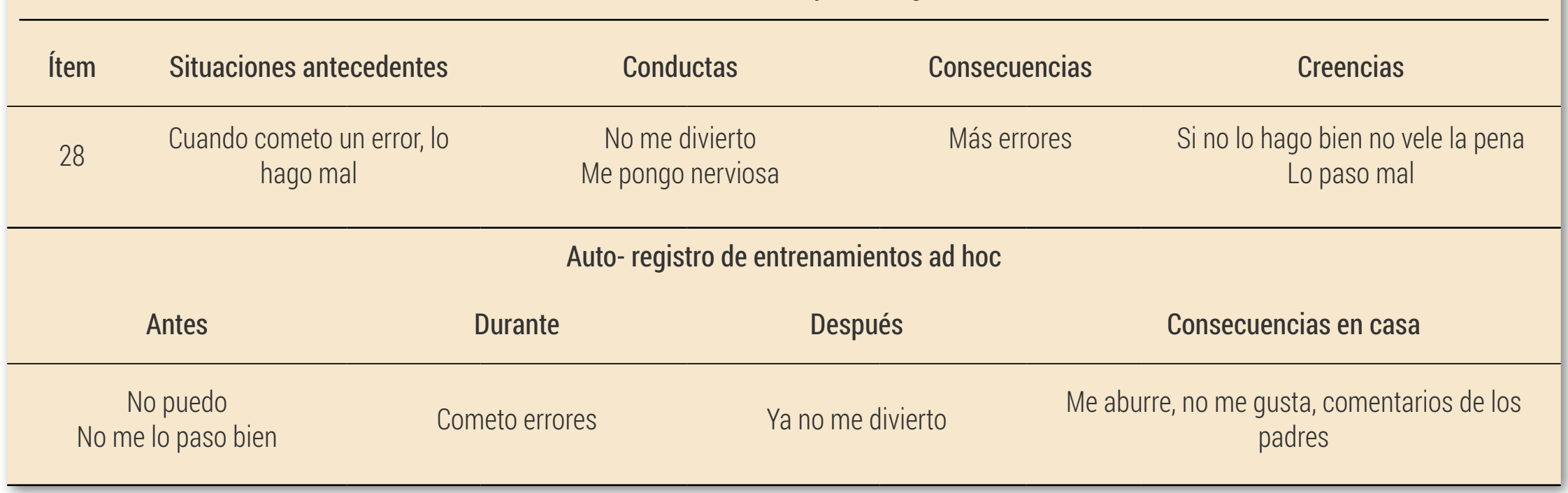

\section{Tabla 3. Esquema de visualización guiada (Coreografía)}

1. Vuelta y media

2. Enlace para levantarme

3. Doble paso mortal al caer en una pierna

4. Enlace para levantarme

5. Pasos de Baile

6. Doble paso lateral de patada

7. Cogida al lado
8. Pasos de baile

9. Doble paso susunova medio giro

10. Revolcón

11. Enlace para levantarme

12. Filc mortal carpado

13. Pasos de bile

14. Cosaco medio giro

15. Pasos de baile
16. Doble paso medio mortal de patada

17. Pasos de baile

18. Pino corzo doblado

19. Me levanto

20. Mortal de parado

21. Doble paso anillo

22. Wenson sin cerrar

23. Final golpes 


\section{Resultados}

Se ha analizado el cuestionario PACES con datos procedentes de dos mediciones: antes de la intervención y posterior a la misma. La primera medición (Figura 1) tiene en cuenta todos los ítems de la escala reducida y en la segunda medición (Figura 2) se han analizado los ítems por separado en dos factores.

En la Figura 1 se puede observar las puntuaciones agrupadas en ítems positivos e ítems negativos. Se consideran en este trabajo positivos los ítems que aportan información sobre el disfrute, asimismo, se han agrupado por su contenido en formato bipolar, los ítems negativos serían sus contrarios ("me gusta vs. no me gusta"). Podemos observar que las puntuaciones han tenido un aumento significativo en el disfrute en general. Las puntuaciones relacionadas con el no disfrute pasan de -26 a -5 .

Los resultados cuantitativos del PACES (Figura 2) muestran un incremento de 7 puntos en el Factor 1, cuyos ítems están relacionados con la motivación primaria. La deportista

Figura 1. PACES (6 items)

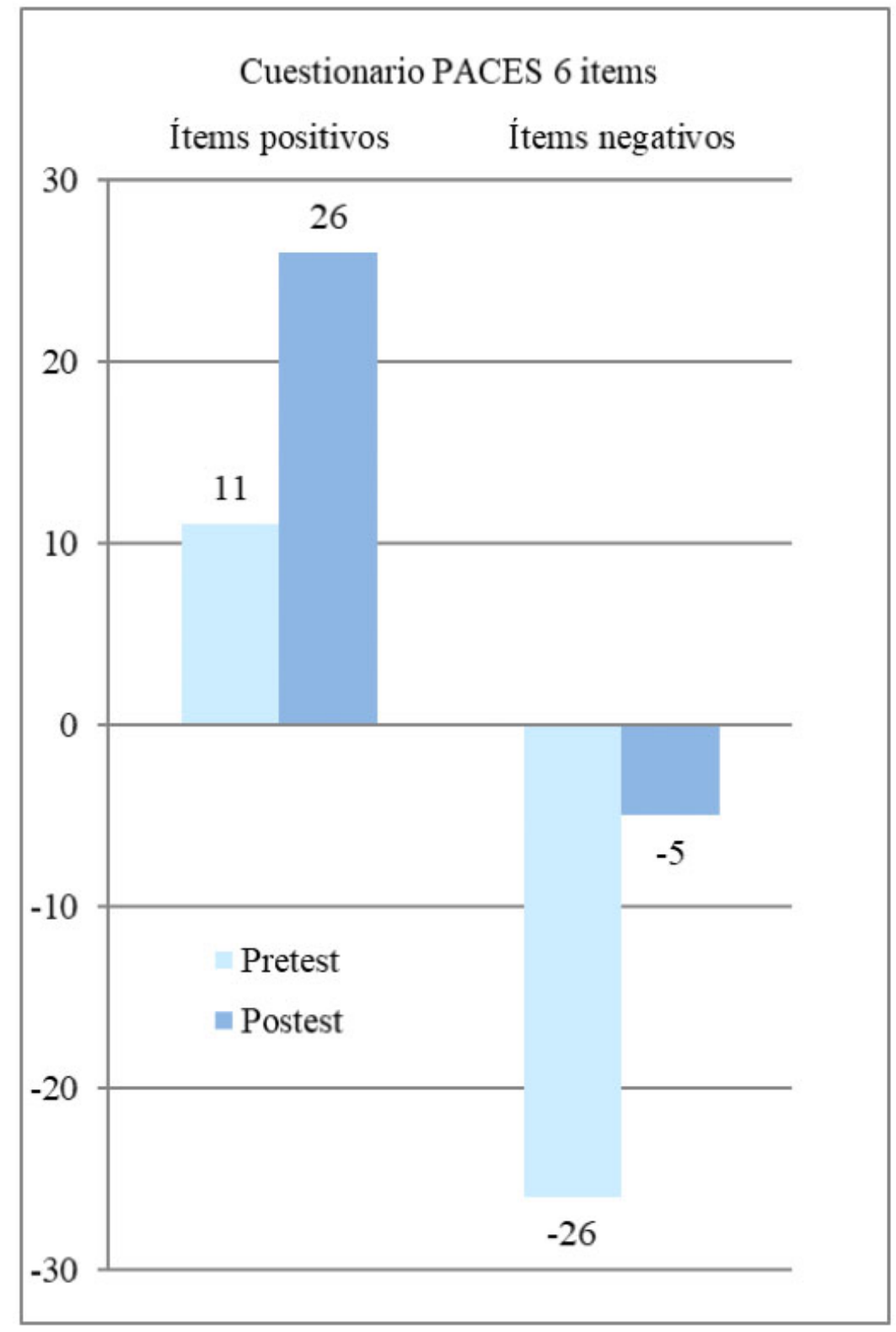

en la fase pre-test respondió a ítems como "me interesa o en muy divertido" con un 2 sobre 5 , y después de la intervención respondió con un 4. Cabe destacar que el ítem "me gusta" pasó de 3 a 5 puntos. En cuanto al Factor 2 relacionados con la percepción de disfrute observamos un incremento de 8 puntos en las puntuaciones.

En la Figura 3 se observan los resultados, que muestran una mejora significativa de los factores "Influencia en la Evaluación del Rendimiento", "Control del Estrés" y "Habilidad Mental", donde se pasó del percentil 49 a 68, del 39 a 82, y del 42 a 89 respectivamente y se constató también un aumento en la "Motivación" cuya puntuación era de 30 y pasó a 90 .

Este incremento entendemos se debe al cambio en las creencias irracionales, las cuales orientaban la atención y esfuerzo casi exclusivamente al control estricto de los errores. Los resultados muestran una mejora de las habilidades mentales de la deportista, quien señala que consigue disfrutar de la actividad deportiva, lo cual redunda en un mejor rendimiento deportivo.

Figura 2. PACES (6 items)

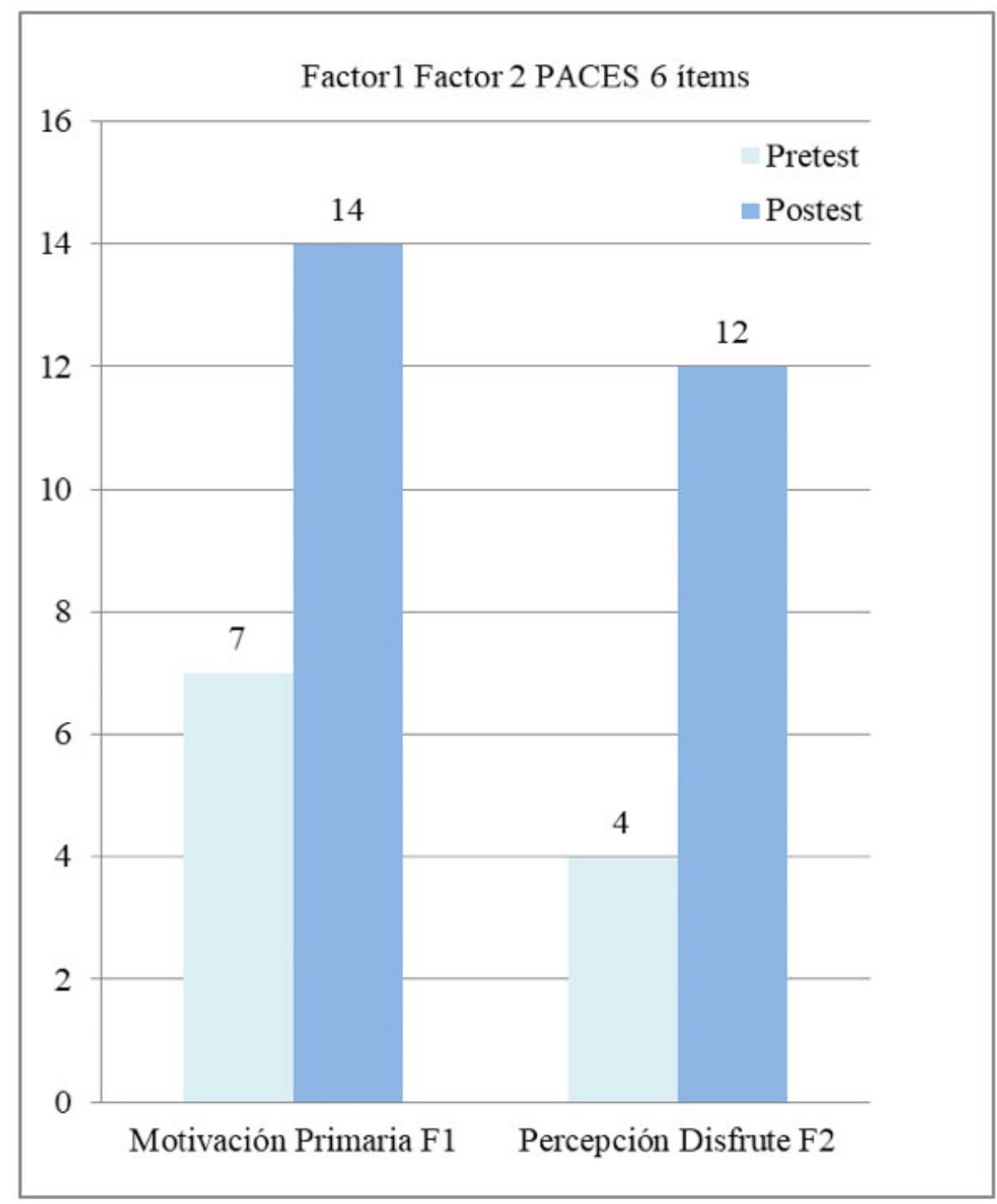


Figura 3. Media de los percentiles en los factores del CPRD, sin el de la escala de "Cohesión"

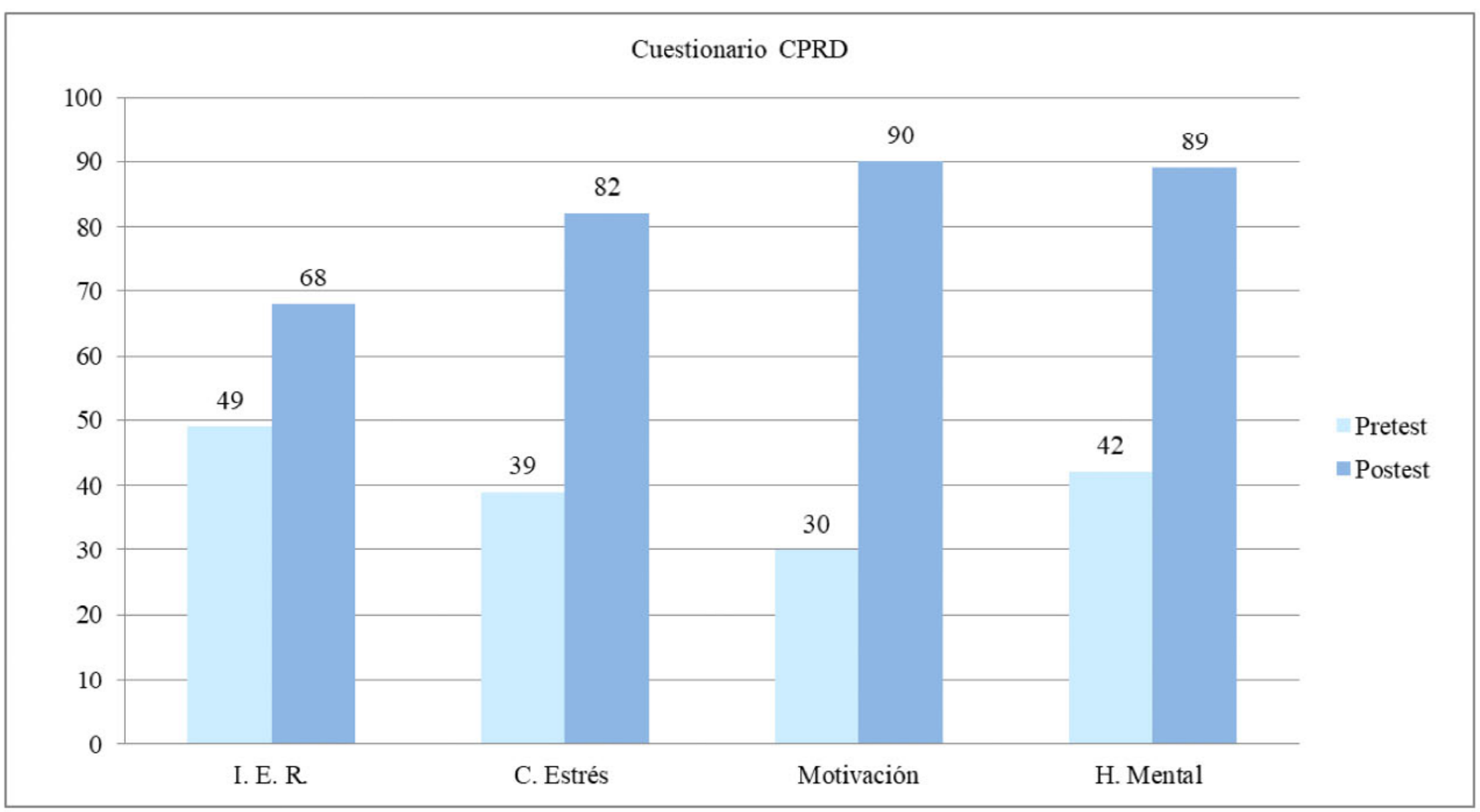

Este cuestionario ha sido útil tanto para la evaluación cuantitativa como para la evaluación cualitativa, ya que algunos ítems han sido utilizados en formato de Análisis Funcional como ya señaló en su día Buceta (1994), que recomiendan este uso en estudios de caso $n=1$. Esta información se ofrece como una valiosa guía para la fase de intervención, al ser posible el análisis de ítems considerados importantes para el caso.

\section{Discusión}

En la intervención se tenían como objetivos: a) que la deportista disfrutara y b) mejorar su rendimiento a través del disfrute -dada la edad de la deportista- y c) indirectamente, prevenir el abandono tempano de la actividad. La variable disfrute se ha mostrado en este estudio esencial para mejorar el rendimiento de la deportista.

A pesar de las limitaciones metodológicas de un estudio de caso único, se demuestra que el disfrute forma parte del proceso motivacional, de la mejora del rendimiento, asimismo previene el abandono prematuro. Las puntuaciones son mejores en el factor 1 relacionado con la motivación intrínseca, lo que se considera fundamental en este caso porque llevaría a realizar la actividad deportiva con el fin de disfrutar de ella, solo por su práctica (motivación intrínseca).
En este caso, este aspecto es relevante porque la deportista comenzó la actividad con 4 años solo por diversión y cuando las demandas derivadas de la práctica se hacen más exigentes empeora su rendimiento y orienta su motivación hacia la idea de no cometer errores, desarrollando entonces ideas irracionales sobre su desempeño que acaban interfiriendo negativamente.

La intervención cognitivo conductual ha resultado eficaz. Lo que confirmaría que el entrenamiento psicológico es altamente eficaz en la mejora del rendimiento de los deportistas, siguiendo el trabajo de Olivares et al. (2016).

La preparación psicológica de los deportistas debe integrarse en el conjunto de su preparación global, como un elemento más que tiene que interactuar, adecuadamente, con la preparación física, técnica y táctica. Considerando todas las vías de obtención de información e influencia psicológica que, permitan comprender y mejorar su funcionamiento deportivo (Buceta, 1998).

Las habilidades psicológicas hacen referencia a factores que influyen en el rendimiento y se encuentran bajo el control del individuo (Weinberg y Gould, 2010). Teniendo en cuenta los resultados se destaca la importancia de un entrenamiento específico para jóvenes deportistas, con el objetivo de incrementar el disfrute y así paralelamente incrementar el rendimiento y como prevención del abandono.

Asimismo, incidir en otras variables influyentes en el rendimiento deportivo, como son la autoconfianza y la orienta- 
ción adecuada de la motivación. Es también imprescindible aplicar y enseñar refuerzos positivos a los deportistas para que los puedan utilizar a modo de auto-habla e instrucciones realistas adecuadas a las metas deportivas.

Los resultados de este estudio son compatibles con los resultados de otros estudios de caso, en los que se realiza una intervención psicológica con medición anterior y posterior del CPRD, como los realizados por Olmedilla y Domínguez (2016) y Peris (2020) en los que se detecta una clara mejoría en las puntuaciones del CPRD después de la intervención.

En el baile deportivo, además, hay que destacar las técnicas relacionadas con el ritmo de la música y con el ritmo de la coreografía, como la atención y concentración, ya que está variable quedan condicionada a determinados pasos y acrobacias.

Se concluye que el entrenamiento psicológico ha sido eficaz para mejorar el desempeño psicológico y el disfrute, así como una percepción de mejora del rendimiento deportivo.

En los estudios de caso único nos encontramos con la limitación metodológica derivada del tiempo de intervención que puede ser demasiado largo y variar con ello las condiciones iniciales del estudio, por lo que el control de las variables intervinientes es más difícil y hay que contemplar algunos cambios que pudieran aparecer en el transcurso de la intervención.

Este tipo de intervención presenta dificultades a la hora de generalizar resultados aun cuando, en este estudio nos hemos centrado en variables relacionadas con el deporte (Buceta, 2016) como el rendimiento. Por otra parte, indicamos la dificultad de argumentar detalladamente la intervención para su posible aplicación posterior en estudios descriptivos es más complejo. Asimismo, al ser fundamentalmente cualitativos y además de caso único, presentan la dificultad de quedar en entredicho la validez externa y la consistencia interna por las propias características de los estudios de caso único cualitativos (Peris, 2021).

A pesar de las limitaciones, este tipo de trabajos son realmente útiles para el psicólogo aplicado y para el avance en las intervenciones psicológicas, buscando intervenciones eficaces en del deporte en diferentes ámbitos, tal y como sugiere Cantón (2016).

Finalmente, de cara a futuros trabajos e investigaciones, indicamos la necesidad de intervenir con los padres para que eduquen a los adolescentes en valores adecuados para el desempeño de la actividad, de modo que no estén basados en la obtención del máximo rendimiento como un objetivo por encima de cualquier cosa.

\section{Referencias}

Buceta, J. M. (1994). El control del nivel de activación en los deportistas: experiencia en baloncesto de alto rendimiento. Apunts. Educación física y Deportes, 1(35), 26-31.

Buceta, J. M. (1998). Psicología del entrenamiento deportivo. Dykinson

Buceta, J. M. (2016). Evaluación psicológica en el deporte. Universidad Nacional de Educación a Distancia.

Cantón, E. (2010). La Psicología del Deporte como profesión especializada. Papeles del Psicólogo, 31(3), 237-245.

Cantón, E. y Checa, I. (2012). Los estados emocionales y su relación con las atribuciones y las expectativas de autoeficacia en el deporte. Revista de Psicología del Deporte, 21(1), 171-176.

Cantón, E. (2016). La especialidad profesional en Psicología del Deporte. Revista de Psicología aplicada al Deporte y al Ejercicio Físico, 1(1), Artículo e2. https://doi.org/10.5093/rpadef2016a2

Castañer, M., Camerino, O. y Anguera, M. T. (2013). Métodos mixtos en la investigación de las ciencias de la actividad física y el deporte. Apunts. Educación Física y Deportes, 112(2), 31-55. https://doi.org/10.5672/apunts.2014-0983.es.(2013/2).112.01

Cox, R. H. (2009). Psicología del deporte: conceptos y sus aplicaciones ( $6^{a}$ ed.). Editorial Médica Panamericana

Davison, K. K., Werder, J. L., Trost, S. G., Baker, B. L. y Birch, L. L. (2007). Why are early maturing girls less active? Links between pubertal development, psychological well-being, and physical activity among girls at ages 11 and 13. Social Science and Medicine, 64(12), 2391-2404

Ezquerro, M. (2015). Evaluación conductual e intervención psicológica en el deporte. En A. García-Naveira y L. Locattelli (eds.), Avances en Psicología del Deporte (pp. 3-33). Paidolibro.

Faggiani, F., Lindern, D., Strey, A., Aiquel, P. F., Fulginiti, D., Sartori, C. y Lisboa, C. S. D. M. (2016). O fenômeno do expatriado no contexto esportivo. Psicologia: Ciência e Profissão, 36, 738-747.

Federación Española de Baile Deportivo (2021). Especialidades. https://www.febd.es/disciplinas/bailes-caribenos-2

García, E. F., Bañuelos, F. S. y Martín, J. S (2008). Validación y adaptación de la escala PACES de disfrute de la práctica de actividad física para adolescentes españolas. Psicothema, 20(4), 890-895.

García, M. D. V. y Rajo, M. M. (2020). Psicología cognitiva. Ediciones Pirámide

García-Naveira, A. y Cantón, E. (2020). Perfil profesional del psicólogo/a del deporte experto/a en esports. Revista de Psicología Aplicada al Deporte y el Ejercicio Físico, 5(2), Artículo e13. https:// doi.org/10.5093/rpadef2020a9

Gimeno, F. y Buceta, J. M. (Eds.). (2010). Evaluación psicológica en el deporte: cuestionario de «características psicológicas relacionadas con el rendimiento deportivo (CPRD). Dykinson.

Hellín, P., Moreno, J. A. y Rodríguez, P. L (2006). Relación de la competencia motriz percibida con la práctica físico-deportiva. Revista de Psicología del Deporte, 15(2), 219-231.

Kendzierski, D. y DeCarlo, K. J. (1991). Physical activity enjoyment scale: Two validation studies. Journal of Sport and Exercise Psychology, 13(1), 50-64.

Kimiecik, J. C. y Harris, A. T. (1996). What is enjoyment? A conceptual/definitional analysis with implications for sport and exer- 
cise psychology. Journal of Sport and Exercise Psychology, 18(3), 247-263.

Labrador, J., Cruzado, J. A. y Muñoz, M. (coords.). (2001). Manual de Técnicas de modificación y terapia de conducta. Pirámide.

Martín, M., Barripedro, M. I., del Castillo, J. M., Jiménez, J. E. y Rivero, A. (2014). Diferencias de género en los hábitos de actividad física de la población adulta en la Comunidad de Madrid. Revista Internacional de Ciencias del Deporte, 38(10), 319-335.

McArdle, S. y Moore, P. (2012). Applying evidence-based principles from CBT to sport psychology. The Sport Psychologist, 26(2), 299-310. https://doi.org/10.1123/tsp.26.2.299

Miras, M. (2001). Afectos, emociones, atribuciones y expectativas: el sentido del aprendizaje escolar. En C. Coll, J. Palacios y A. Marchesi (Eds.), Desarrollo psicológico y educación, (Vol. 2 - Psicología de la educación escolar, pp. 309-329). Alianza.

Mokaberian, M., Kashani, V. y Sedighi-Faroji, F. (2018). Validation of the Persian version of Physical Activity Enjoyment Scale in Children. Motor Behavior, 9(30), 17-36. https://doi:10.22089/ mbj.2018.3095.1382

Olivares. E. M, García, J. J. y Garcés, E. J. (2016). Entrenamiento psicológico en tiro olímpico: Estudio de un caso. Revista de Psicología del Deporte, 25(1), 131-135.

Olivares, E. y López, J.E. (2016). Entrenamiento psicológico en tiro olímpico: Estudio de un caso Entrenamiento psicológico en tiro olímpico: un estudio de caso. Revista de Psicología del Deporte, 25(1), 131-135.

Olmedilla, A. y Domínguez, J. (2016). Entrenamiento psicológico para la mejora de la atención y la autoconfianza en un futbolista. Revista de Psicología Aplicada al Deporte y al Ejercicio Físico, 1(1), Artículo e4. https://doi.org/10.5093/rpadef2016a4

Peris, D. (2020a). Diez ideas potenciadoras para rendir al máximo en el deporte. Revista de Psicología Aplicada al Deporte y el
Ejercicio Físico, 5(2), Artículo e11. https://doi.org/10.5093/rpadef2020a10

Peris, D. (2021). Intervención psicológica en un jugador de pádel competitivo: un estudio de caso. Revista de Psicología Aplicada al Deporte y al Ejercicio Físico, 6(1), Artículo e3. https://doi. org/70.5093/rpadef2021a2

Peris, D. y Cantón, E. (2018). El perfil profesional del psicólogo especialista en psicología del deporte en fútbol. Revista de Psicología Aplicada al Deporte y el Ejercicio Físico, 3(1), Artículo e9. https://doi.org/10.5093/rpadef2018a6

Ryan, R. y Deci, E. L. (2000). La Teoría de la Autodeterminación y la Facilitación de la Motivación Intrínseca, el Desarrollo Social, y el Bienestar. American Psychologist, 55(1), 68-78.

Sallis, J. F., Prochaska, J. J. y Taylor, W. C. (2000). A review of correlates of physical activity of children and adolescents. Medicine and Science in Sports and Exercise, 32(5), 963-975.

Scanlan, T. K., Carpenter, P. J., Schmidt, G. W., Simons, J. P. y Keeler, B. (1993). An introduction to the Sport Commitment Model. Journal of Sport and Exercise Psychology, 15, 1-15.

Simons, H. (2011). El estudio de caso: teoría y práctica. Morata.

Stake, R.E. (2020). Investigación con estudio de casos (sexta edición). Morata.

Subramanian, P. R. y Silverman, S. (2000). Validation of scores from an instrument assessing student attitude toward physical education. Measurement in Physical Education and Exercise Science, 4(1), 29-43.

Weinberg, R. S. y Gould, D. (2010). Fundamentos de Psicología del Deporte. Ariel.

Yalcin, I. y Ramazanoglu, F. (2020). El efecto del uso de imágenes en la autoconfianza: futbolistas profesionales turcos. Revista de Psicología del Deporte, 29(2), 57-64. 